\title{
Protection of the environment from ionising radiation in a regulatory context (PROTECT): Assessment approaches - practicality, relevance and merits
}

\author{
N.A. Beresford ${ }^{1}$, K. Beaugelin-Seiller ${ }^{2}$, J.E. Brown ${ }^{3}$, D. Copplestone ${ }^{4}$, \\ A. Hosseini ${ }^{3}$, P. Andersson ${ }^{5}$ and B.J. Howard ${ }^{1}$ \\ ${ }^{1}$ Centre for Ecology \& Hydrology, CEH-Lancaster, Lancaster Environment Centre, \\ Library Av., Bailrigg, Lancaster LA1 4AP, UK \\ ${ }^{2}$ Institut de Radioprotection et de Sûreté Nucléaire, France \\ ${ }^{3}$ Norwegian Radiation Protection Authority, Norway \\ ${ }^{4}$ England \& Wales Environment Agency, UK \\ ${ }^{5}$ Swedish Radiation Protection Authority, Sweden \\ e-mail: nab@ceh.ac.uk
}

\begin{abstract}
In common with the assessment of chemical stressors many of the methods used for the assessment of risk of non-human biota exposed to radiation use tiered approaches. The initial tier within these approaches is designed to be simple and conservative with the aim to identify sites of negligible concern which can be excluded from more detailed assessment with a high degree of confidence. In this paper we compare the outputs of the screening tiers of three tools which are freely available as software packages. Outputs were compared for terrestrial and freshwater ecosystems assuming $1 \mathrm{~Bq}$ per unit media. Considerable variability between the risk quotients (RQ) estimated by the three approaches used was seen for some radionuclide-organism-ecosystem combinations. Reasons for this are explored with differences in transfer parameters used by the models being a common contributor. The large variation within RQ values estimated by the approaches requires further investigation as it does not promote the level of confidence required by the user. The practicalities of applying a single generic screening dose rate in assessments are also explored.
\end{abstract}

\section{INTRODUCTION}

A number of models/approaches/tools to estimate the exposure of wildlife to ionising radiation have been produced or are being developed for use in assessments [1-3]. Many of the approaches use some form of tiered (iterative) assessment consistent with approaches used for other stressors. Such tiered assessments begin with a highly conservative screening tier and progress, if required, to more refined assessments. Some of these approaches are freely available as software packages, these are: (i) RESRAD-BIOTA which implements the graded approach described by USDOE [4]; (ii) the ERICA Tool developed by a EURATOM funded project [5]; (iii) the R\&D128 methodology developed by the England \& Wales Environment Agency (EA) [6, 7].

This paper describes part of the work being conducted by the EURATOM funded PROTECT project to assess the relative merits (in terms of complexity, fitness for purpose, cost and robustness) of assessment approaches. Links to the software and documentation for the three approaches considered can be found on http://www.ceh.ac.uk/protect/pages/env_protect_radio.html.

\section{MODEL DESCRIPTIONS}

The initial screening level of tiered approaches is designed to be simple, require minimal inputs and provide conservative results. The aim is to identify sites of negligible concern and to remove them from further consideration with a high degree of confidence. This paper is focused on the comparison of the 
screening level application of the three approaches being considered, and the following descriptions concentrate on this tier of the models.

\subsection{RESRAD-BIOTA}

The RESRAD-BIOTA code was designed to be consistent with, and provide a tool for, implementing the graded approach for biota dose assessment [4]. The recommended inputs for screening level assessments are maximum media activity concentrations. These are compared to biota concentration guidelines (BCG) which are the estimated media concentration for which the corresponding dose rate is equal to the screening dose rate; the output is the ratio of input media activity concentrations to the BCG. The model presents a combined 'ecosystem' ratio (e.g. combining sediment and water ratios) which is estimated from individual media ratios for different organisms. The BCGs are estimated assuming: infinitely large and small geometries for internal and external dose calculations respectively; $100 \%$ of time in soil (terrestrial) or at the sediment-water interface (aquatic); generally conservative parameters to estimate biota activity concentrations; screening dose rates of $1 \mathrm{mGy} \mathrm{d}^{-1}$ ( $\operatorname{circa} 40 \mu \mathrm{Gy} \mathrm{h}^{-1}$ ) for terrestrial and riparian animals, and $10 \mathrm{mGy} \mathrm{d}^{-1}\left(\operatorname{circa} 400 \mu \mathrm{Gy} \mathrm{h}^{-1}\right)$ for terrestrial plants and aquatic animals. For terrestrial plants and aquatic animals, maximum biota to media concentration ratios (CRs), largely identified from published literature reviews, are used in the derivation of BCGs. For terrestrial and riparian animals $95^{\text {th }}$ percentile $\mathrm{CR}$ values predicted using an allometric approach are used. Best estimate distribution coefficient $\left(\mathrm{k}_{\mathrm{d}}\right)$ values are used. Four generic organisms are considered in the screening tier: terrestrial plants; terrestrial animals; aquatic animals; riparian animals. The BCGs are estimated assuming the following exposure routes:

- Aquatic animals

- Sediment - external exposure due to contaminated sediment

- Water - internal and external exposure due to contaminated water

- Riparian animals

- Sediment - internal and external exposure due to contaminated sediment

- Water - internal and external exposure due to contaminated water

- Terrestrial animals

- Soil - internal and external exposure due to contaminated soil

- Water - internal and external exposure due to contaminated water

- Terrestrial plants

- Soil - internal and external exposure due to contaminated soil

- Water - external exposure due to contaminated water.

\subsection{The ERICA tool}

The ERICA Tool [5] implements the tiered approach of the ERICA Integrated Approach [8]. Transfer from contaminated media to a range of terrestrial and aquatic reference organisms is estimated using biota whole-body to media CRs, predominantly derived from the literature; sediment $\mathrm{k}_{\mathrm{d}} \mathrm{s}$ are also used in aquatic ecosystems. In total, 40 reference organisms are considered; these are approximately equally divided between terrestrial, freshwater and marine ecosystems. For dosimetry, reference organisms are defined as simple, three-dimensional phantoms, i.e. ellipsoids and cylinders, as model geometric equivalents of reference organisms according to average characteristics of mass and size.

The inputs into the screening tier of the ERICA Tool are recommended to be the maximum measured or modelled media activity concentrations. Using probability distribution functions (pdfs) 
of the default transfer database and conservative habitat assumptions, $95^{\text {th }}$ percentile environmental media concentration limits (EMCLs) have been estimated [5]. The EMCL is the media concentration (for a given radionuclide) for which the corresponding dose rate equals the screening dose. The ERICA Tool contains EMCLs for a default generic screening dose rate of $10 \mu \mathrm{Gy} \mathrm{h}^{-1}$ for all organisms and ecosystems. It also contains EMCLs for screening dose rates of $40 \mu \mathrm{Gy} \mathrm{h}^{-1}$ for terrestrial animals and $400 \mu \mathrm{Gy} \mathrm{h}^{-1}$ for terrestrial plants and all organisms in aquatic environments. The outputs of the screening tier are risk quotients (i.e. ratio of input media concentration to the EMCL) for the most limiting organism. A difference to the RESRAD-BIOTA approach is that for aquatic ecosystems, the EMCL for water includes consideration of external exposure from sediments (in addition to internal exposure and external exposure from water). Similarly, the EMCL for sediment includes external exposure from water and internal exposure (estimated using $\mathrm{k}_{\mathrm{d}}$ and $\mathrm{CR}$ values).

\subsection{England \& Wales Environment Agency R\&D128}

This model [6, 7] uses a similar approach to ERICA, although a more limited set of organisms and radionuclides are considered. Whilst this simple spreadsheet model does not have in-built tiers the method of application to assessments, it is broadly compatible to the tiered approaches of the other models [8] with maximum inputs being used in initial screening assessments. When applied by the England and Wales Environment Agency in screening assessments, results are compared to a screening level dose rate of $5 \mu \mathrm{Gy} \mathrm{h}^{-1}$ with $40 \mu \mathrm{Gy} \mathrm{h}^{-1}$ being used as an upper action level.

\section{METHODS}

All three models were run assuming $1 \mathrm{~Bq}$ per unit media (terrestrial soil, freshwater sediment and freshwater water) for the 36 radionuclides common to both RESRAD-BIOTA and the ERICA Tool (not all of these radionuclides are considered within R\&D 128). To be comparable to the RESRADBIOTA BCG values, the ERICA Tool was run using screening dose rates of $40 \mu \mathrm{Gy} \mathrm{h}^{-1}$ for terrestrial animals and $400 \mu \mathrm{Gy} \mathrm{h}^{-1}$ for terrestrial plants and all organisms in aquatic environments. Results of R\&D 128 were compared to the same screening dose rates as the ERICA Tool. Note the ERICA Tool version used was that available in January 2008, a test version of RESRAD-BIOTA (version 1.22 Beta (created 12/01/06)) made available by the tool developers (Argonne National Laboratory) was used, the R\&D128 spreadsheets used were v1.15 and v1.20 for freshwater and terrestrial ecosystems respectively.

\section{RESULTS}

Model outputs were compared as the risk quotients (RQs), where the RQ for RESRAD-BIOTA and the ERICA Tool are the ratio of media concentration to the BCG and EMCL, respectively. For R\&D 128 , the RQ was calculated as the ratio of the estimated dose rate to the screening dose rate. Only the highest RQ for any radionuclide were considered. Table 1 present RQ values estimated for freshwater organisms assuming $1 \mathrm{Bql}^{-1}$ in water for those radionuclides common to all three models. The RQ values reported for RESRAD-BIOTA are the 'ecosystem' value. Table 1 demonstrates considerable variability between estimated RQ values for some radionuclides; similar variability was observed in RQ values for terrestrial organisms when the models were run assuming $1 \mathrm{~Bq} \mathrm{~kg}^{-1}$ soil. Variability was generally greater when the models were run assuming $1 \mathrm{~Bq} \mathrm{~kg}^{-1}$ (dry weight) in freshwater sediments with 11 of the 36 estimated RQ values varying between models by more than two orders of magnitude (note this comparison was only conducted for the ERICA Tool and RESRAD-BIOTA as the R\&D128 spreadsheets only allow the user to input activity concentrations for water). 


\section{DISCUSSION}

\subsection{Variation in estimated $R Q$ values}

There are a number of factors, including the differences in exposure routes described above, which contribute to the variability observed in the estimated RQ values between the three models.

The ERICA Tool and R\&D128 consider a greater range of organisms compared to the four generic organisms considered in RESRAD-BIOTA. Some of these (e.g. phytoplankton, lichen) tend to accumulate high concentrations of some radionuclides and are consequently identified as the most limiting organisms with comparatively high RQ values as demonstrated in Table 1 (see also section 5.2 below).

Default radiation weighting factors for alpha and low energy beta emitters differ between the three models. Both the ERICA Tool and R\&D128 assume a radiation weighting factor of 3 for low energy beta emitters (a weighting factor is not used in RESRAD BIOTA). The ERICA Tool uses a weighting factor of 10 for alpha emitters, whilst RESRAD-BIOTA and R\&D128 assume a value of 20. Therefore, the differences in default radiation weighting factors should add no more than a three-fold variation to any $R Q$ value (i.e. for a low energy beta emitter).

Table 1. Comparison of estimated RQ values and limiting organisms for freshwater ecosystems assuming an activity concentration in water of $1 \mathrm{~Bq}^{-1}$.

\begin{tabular}{|c|c|c|c|c|c|c|}
\hline Nuclide & $\begin{array}{l}\text { RESRAD- } \\
\text { BIOTA }\end{array}$ & $\begin{array}{c}\text { ERICA } \\
\text { Tool } \\
\text { RQ }\end{array}$ & $\begin{array}{c}\text { EA } \\
\text { R\&D128 }\end{array}$ & $\begin{array}{l}\text { RESRAD- } \\
\text { BIOTA }\end{array}$ & $\begin{array}{l}\text { ERICA Tool } \\
\text { Limiting organ }\end{array}$ & EA R\&D128 \\
\hline H-3 & $1.02 \mathrm{E}-07$ & $6.96 \mathrm{E}-08$ & $2.46 \mathrm{E}-08$ & Riparian animal & Phytoplankton & All organisms \\
\hline C-14 & $4.43 \mathrm{E}-02$ & $1.54 \mathrm{E}-03$ & $5.20 \mathrm{E}-04$ & Riparian animal & Bird & Duck \\
\hline Co-60 & $2.57 \mathrm{E}-02$ & $1.28 \mathrm{E}+00$ & $7.50 \mathrm{E}-03$ & Aquatic animal & Insect larvae & Bacteria \\
\hline Sr-90 & $9.85 \mathrm{E}-02$ & $6.84 \mathrm{E}-03$ & $1.89 \mathrm{E}-03$ & Riparian animal & Insect larvae & Duck \\
\hline Tc-99 & 4.37E-05 & $4.75 \mathrm{E}-04$ & $1.90 \mathrm{E}-04$ & Riparian animal & Vascular plant & Duck \\
\hline $\mathrm{I}-129$ & 7.12E-04 & 8.71E-04 & $7.84 \mathrm{E}-05$ & Riparian animal & Phytoplankton & Duck \\
\hline I-131 & 2.02E-03 & $1.15 \mathrm{E}-03$ & $2.06 \mathrm{E}-04$ & Riparian animal & Phytoplankton & Duck \\
\hline Cs-137 & $6.38 \mathrm{E}-01$ & 4.70E-01 & $5.03 \mathrm{E}-03$ & Riparian animal & Insect larvae & Duck \\
\hline Po-210 & 7.42E-02 & $8.86 \mathrm{E}+00$ & $1.56 \mathrm{E}+01$ & Aquatic animal $^{1}$ & Bivalve mollusc & $\begin{array}{l}\text { Benthic } \\
\text { mollusc \& } \\
\text { Benthic } \\
\text { crustacean }\end{array}$ \\
\hline Th-234 & $3.75 \mathrm{E}-01$ & $2.57 \mathrm{E}+01$ & $1.24 \mathrm{E}-02$ & Aquatic animal ${ }^{1}$ & Insect larvae & Duck \\
\hline $\mathrm{U}-238$ & $1.22 \mathrm{E}-01$ & $4.87 \mathrm{E}-01$ & $1.68 \mathrm{E}+00$ & Aquatic animal $^{1}$ & Vascular plant & $\begin{array}{l}\text { Amphibian \& } \\
\text { Duck }\end{array}$ \\
\hline $\mathrm{Pu}-239$ & $1.54 \mathrm{E}-01$ & $1.05 \mathrm{E}+00$ & $1.48 \mathrm{E}+01$ & Aquatic animal $^{1}$ & Phytoplankton & Amphibian \\
\hline Am-241 & 8.79E-02 & $9.12 \mathrm{E}+00$ & $6.32 \mathrm{E}+00$ & Aquatic animal $^{1}$ & Phytoplankton & Amphibian \& Duck \\
\hline
\end{tabular}

${ }^{1}$ Note this is the limiting organism compared to the water BCG value; Riparian animal is the limiting organism against the sediment BCG in all instances considered here.

There is a difference in how RESRAD-BIOTA and the ERICA Tool consider organisms such as mammals, amphibians and birds which may be exposed in both terrestrial and aquatic environments. The ERICA Tool assesses these organisms against a screening dose rate of $40 \mu \mathrm{Gy} \mathrm{h}^{-1}$ in terrestrial ecosystems and $400 \mu \mathrm{Gy} \mathrm{h}^{-1}$ in aquatic ecosystems. Within RESRAD-BIOTA, these organisms are considered as the generic 'riparian animal' for which a screening dose rate of $40 \mu \mathrm{Gy} \mathrm{h}^{-1}$ is (in our opinion more logically) applied regardless of contamination route. The consequence of this difference is that for such animals RESRAD-BIOTA will result in an RQ one order of magnitude greater than that estimated by the ERICA Tool (N.B. whilst the 40 and $400 \mu \mathrm{Gy} \mathrm{h}^{-1}$ screening dose rates, implemented as described, are an option within the ERICA Tool the default option is a generic screening dose rate of $10 \mu \mathrm{Gy} \mathrm{h}^{-1}$ ). 
A common contributor to variation in estimated RQ values is the different default $\mathrm{CR}$ and $\mathrm{k}_{\mathrm{d}}$ values used within the models. In part, this is a consequence of the different organisms considered in the three models. It is also in agreement with other comparisons of models/approaches used to estimate exposure of biota which have demonstrated that the dosimetry components generally estimate comparable results [1-3]. The greater variability observed in estimated RQ values between models when assuming $1 \mathrm{~Bq} \mathrm{~kg}^{-1}$ in freshwater sediments may be the consequence of RESRAD-BIOTA using terrestrial soil-soil water $\mathrm{k}_{\mathrm{d}}$ values rather than freshwater sediment-water $\mathrm{k}_{\mathrm{d}}$ values [10].

The three approaches considered in this paper are readily available for regulators/industry to use within assessments. Application in screening assessments is supposed to enable the user to, with minimal effort but a high degree of confidence, decide if sites can be considered to present negligible risk and be excluded from further assessment. It is anticipated that such screening level assessments will be the most common use of these models when applied to planned releases. The large variation within RQ values estimated by the approaches requires further investigation as it does not promote the level of confidence required by the user. Furthermore, this work adds to the recommendations made elsewhere [2] that there is a clear need to better share knowledge on the parameterisation of radionuclide transfer to biota and to provide authoritative collations of those data which are available.

\subsection{The application of generic screening values}

As noted above (and evident from Table 1) a contributor to the variation in RQ values estimated between the three models is differences in the organisms considered. R\&D 128, and especially the ERICA Tool, consider a greater range of organisms than RESRAD-BIOTA including some which accumulate comparatively high activity concentrations of some radionuclides. Whilst in this paper we have considered the application of screening dose rates which, in a limited way, vary between organism types and ecosystems, a generic screening dose rate across all organism types is the default option within the ERICA Tool. This is also the approach used in the United Kingdom when applying the R\&D 128 methodology [9]. Consideration of the estimation of a scientifically robust generic screening dose rate is also an aim of the PROTECT project [11]. However, there are consequences of the assessment methodology which impact on the practicality of this aim. For instance, for 59 of the 63 radionuclides considered within the ERICA Tool invertebrate organisms, plankton and vascular plant are the limiting freshwater organism when the default generic screening dose rate of $10 \mu \mathrm{Gy} \mathrm{h}^{-1}$ is applied (bird and amphibian each being the limiting organism for two of the remaining radionuclides). For terrestrial ecosystems, vertebrate reference organisms are limiting for only 19 radionuclides whilst plants and invertebrates are the limiting reference organism for 44 radionuclides. Vertebrates are the limiting organism in the marine ecosystem for only 7 of the 63 radionuclides considered.

When applying a single screening dose rate, the assessment tools always identify the most exposed organism as the most limiting. However, vertebrate species, which are generally considered to be the most sensitive to radioactivity [12], are most often not those estimated to be the most exposed. Consequently, the use of a generic screening dose rate designed to protect all species types may not identify the most 'at risk' organism, as more exposed, but less radiosensitive organisms are likely to be identified as rate limiting although they are at lower risk. Whilst this will mean that the assessment is being conservative, it is likely that it may be overly so, resulting in the need for assessments beyond a simple screening tier when this may not be scientifically justified. This has lead to the proposition of benchmark dose rate values for various organism groups and this issue is discussed further by [11].

\section{Acknowledgments}

The authors would like to thank the participants of the two workshops (held in Vienna, June 2007, and Oslo, January 2008) associated with this work package (see http://www.ceh.ac.uk/protect/pages/workshops.html). This work was supported by the EC-EURATOM $6^{\text {th }}$ Framework Programme and forms part of the PROTECT project (FI6R-036425); the financial support of the EC is gratefully acknowledged. 


\section{References}

[1] Beresford N.A., Balonov M., Beaugelin-Seiller K., Brown J., Copplestone D., Hingston J.L., Horyna J., Hosseini A., Howard B.J., Kamboj S., Nedveckaite T., Olyslaegers G., Sazykina T., Vives i Batlle J., Yankovich T.L. and Yu C., Appl. Radiat. Isot. Available on line: doi:10.1016/j.apradiso.2008.04.009 (2008).

[2] Beresford N.A., Barnett C.L., Beaugelin-Seiller K., Brown J.E., Cheng J-J., Copplestone D., Gaschak S., Hingston J.L., Horyna J., Hosseini A., Howard B.J., Kamboj S., Kryshev A., Nedveckaite T., Olyslaegers G., Sazykina T., Smith J.T., Telleria D., Vives i Batlle J., Yankovich T.L., Heling R., Wood M.D. and Yu C., Radioprotection (this issue).

[3] Vives i Batlle J., Balonov M., Beaugelin-Seiller K., Beresford N.A., Brown J., Cheng J-J., Copplestone D., Doi M., Filistovic V., Golikov V., Horyna J., Hosseini A., Howard B.J., Jones S.R., Kamboj S., Kryshev A., Nedveckaite T., Olyslaegers G., Pröhl G., Sazykina T., Ulanovsky A., Vives Lynch S., Yankovich T. and Yu C., Rad. Environ. Biophys. 46 (2007) 349-373.

[4] USDOE, A graded approach for evaluating radiation doses to aquatic and terrestrial biota, Technical Standard DOE-STD-1153-2002 (United States Department of Energy, Washington DC, 2002).

[5] Brown J.E., Alfonso B., Avila R., Beresford N.A., Copplestone D., Pröhl G. and Ulanovsky A., J. Environ. Radioact. Available on line: doi:10.1016/j.jenvrad.2008.01.008 (2008).

[6] Copplestone D., Bielby S., Jones S.R., Patton D., Daniel P. and Gize I., Impact assessment of ionising radiation on wildlife, R\&D Publication 128, ISBN: 185705590 X. (Environment Agency, Bristol, 2001).

[7] Copplestone D., Wood M.D., Bielby S., Jones S.R., Vives i Batlle J. and Beresford N.A., Habitat regulations for Stage 3 assessments: radioactive substances authorisations (R\&D Technical Report P3-101/SP1a, Environment Agency, Bristol, 2003).

[8] Larsson C.-M., J. Environ. Radioact., Available on line: doi:10.1016/j.jenvrad.2007.11.019 (2008).

[9] Allott R. and Copplestone D., Update on habitats assessments for England and Wales. National Dose Assessment Working Group, Paper 13-04, Available from: http://www.ndawg.org/ documents/Paper13-04.pdf (2008).

[10] Beresford N.A., Anderson P., Beaugelin-Seiller K., Brown J., Copplestone D., Garnier-Laplace J., Hosseini, A., Howard B.J. and Oughton, D.H., Approaches to demonstrate protection of the environment from ionising radiation, Workshop report for the EC EURATOM PROTECT project (Contract Number: 036425 (FI6R)), Available from: http://www.ceh.ac.uk/protect (2008).

[11] Andersson P., Beaugelin-Seiller K., Beresford N.A., Copplestone D., Della Vedova C., GarnierLaplace J., Howard B.J., Howe P. and Oughton D.H., Numerical benchmarks for protecting biota against radiation in the environment: proposed levels and underlying reasoning, Deliverable 5B (draft) of the EC EURATOM PROTECT project (Contract Number: 036425 (FI6R)), Available from: http://www.ceh.ac.uk/protect (2008).

[12] UNSCEAR, Sources and effects of ionizing radiation, Report to the general assembly with scientific annex, United Nations scientific committee on the effects of atomic radiation (United Nations, New York, 1996). 